\title{
The Biologic Response to Polyetheretherketone (PEEK) Wear Particles in Total Joint Replacement: A Systematic Review
}

\author{
Ashley A. Stratton-Powell MSc, Kinga M. Pasko MSc, Claire L. Brockett PhD, \\ Joanne L. Tipper PhD
}

Received: 20 November 2015/Accepted: 6 July 2016/Published online: 18 July 2016

(C) The Author(s) 2016. This article is published with open access at Springerlink.com

\begin{abstract}
Background Polyetheretherketone (PEEK) and its composites are polymers resistant to fatigue strain, radiologically transparent, and have mechanical properties suitable for a range of orthopaedic applications. In bulk form, PEEK composites are generally accepted as biocompatible. In particulate form, however, the biologic response relevant to joint replacement devices remains unclear. The biologic response to wear particles affects the longevity of total joint arthroplasties. Particles in the phagocytozable size range of $0.1 \mu \mathrm{m}$ to $10 \mu \mathrm{m}$ are considered the most biologically reactive, particularly particles with a mean size of $<1 \mu \mathrm{m}$. This systematic review aimed to identify the current evidence for the biologic response to PEEK-based wear debris from total joint arthroplasties.

Questions/purposes (1) What are the quantitative characteristics of PEEK-based wear particles produced by total joint arthroplasties? (2) Do PEEK wear particles cause an

One or more of the authors (AAS-P, KMP) are funded by studentships provided by the Engineering and Physical Sciences Research Council (EPSRC) as part of the EPSRC Doctoral Training Centre in Tissue Engineering and Regenerative Medicine, a collaboration among the Universities of Leeds, Sheffield, and York, grant No. EP/500513/1. All ICMJE Conflict of Interest Forms for authors and Clinical Orthopaedics and Related Research ${ }^{\mathbb{R}}$ editors and board members are on file with the publication and can be viewed on request.

Clinical Orthopaedics and Related Research ${ }^{\mathbb{R}}$ neither advocates nor endorses the use of any treatment, drug, or device. Readers are encouraged to always seek additional information, including FDAapproval status, of any drug or device prior to clinical use.
\end{abstract}

A. A. Stratton-Powell, K. M. Pasko, C. L. Brockett,

J. L. Tipper $(\square)$

Institute of Medical and Biological Engineering, School of

Mechanical Engineering, University of Leeds, Leeds LS2 9JT,

UK

e-mail: J.L.Tipper@leeds.ac.uk adverse biologic response when compared with UHMWPE or a similar negative control biomaterial? (3) Is the biologic response affected by particle characteristics?

Methods Embase and Ovid Medline databases were searched for studies that quantified PEEK-based particle characteristics and/or investigated the biologic response to PEEK-based particles relevant to total joint arthroplasties. The keyword search included brands of PEEK (eg, MITCH, MOTIS) or variations of PEEK types and nomenclature (eg, PAEK, CFR-PEEK) in combination with types of joint (eg, hip, knee) and synonyms for wear debris or immunologic response (eg, particles, cytotoxicity). Peer-reviewed studies, published in English, investigating total joint arthroplasty devices and cytotoxic effects of PEEK particulates were included. Studies investigating devices without articulating bearings (eg, spinal instrumentation devices) and bulk material or contact cytotoxicity were excluded. Of 129 studies, 15 were selected for analysis and interpretation. No studies were found that isolated and characterized PEEK wear particles from retrieved periprosthetic human tissue samples.

Results In the four studies that quantified PEEK-based particles produced using hip, knee, and spinal joint replacement simulators, the mean particle size was $0.23 \mu \mathrm{m}$ to $2.0 \mu \mathrm{m}$. The absolute range reported was approximately $0.01 \mu \mathrm{m}$ to $50 \mu \mathrm{m}$. Rod-like carbon particulates and granular-shaped PEEK particles were identified in human tissue by histologic analysis. Ten studies, including six animal models (rat, mouse, and rabbit), three cell line experiments, and two human tissue retreival studies, investigated the biologic response to PEEK-based particles. Qualitative histologic assessments showed immunologic cell infiltration to be similar for PEEK particles when compared with UHMWPE particles in all six of the animal studies identified. However, increased inflammatory 
cytokine release (such as tumor necrosis factor- $\alpha$ ) was identified in only one in vitro study, but without substantial suppression in macrophage viability. Only one study tested the effects of particle size on cytotoxicity and found the largest unfilled PEEK particles (approximately $13 \mu \mathrm{m}$ ) to have a toxic effect; UHMWPE particles in the same size range showed a similar cytotoxic effect.

Conclusions Wear particles produced by PEEK-based bearings were, in almost all cases, in the phagocytozable size range $(0.1-10 \mu \mathrm{m})$. The studies that evaluated the biologic response to PEEK-based particles generally found cytotoxicity to be within acceptable limits relative to the UHMWPE control, but inconsistent when inflammatory cytokine release was considered.

Clinical Relevance To translate new and advanced materials into clinical use more quickly, the clinical relevance and validity of preclinical tests need to be improved. To achieve this for PEEK-based devices, human tissue retrieval studies including subsequent particle isolation and characterization analyses are required. In vitro cell studies using isolated wear particles from tissue or validated joint replacement simulators, instead of manufactured particles, are also required.

\section{Introduction}

Successful clinical performance of total joint arthroplasties (TJAs) can be determined by many factors, including material, biomechanical, and tribologic design considerations. In particular, it has been established that wear and the biologic reactivity of wear particles play a key role in longterm implant survivorship [1]. Wear particles produced by joint arthroplasty materials, in particular ultrahigh-molecular-weight polyethylene (UHMWPE), have been implicated in late aseptic loosening and subsequent joint failure [8, 16, 18, 30, 37, 39]. Immunologic cells such as macrophages phagocytoze the debris material, which initiates the release of inflammatory cytokines and stimulates osteoclastic bone resorption [21]. Particle size, morphology, volume, and composition are associated with biologic reactivity [28]. The specific size and composition of particles most likely to be biologically reactive remain a controversial topic, particularly among similar biomaterials such as UHMWPE, highly crosslinked UHMWPE, and vitamin $\mathrm{E}$ highly crosslinked UHWMPE [2, 10, $11,20,31,32,41,42]$. Particles in the phagocytozable size range of $0.1 \mu \mathrm{m}$ to $10 \mu \mathrm{m}$ are considered the most biologically reactive, particularly particles with a mean size of $<1 \mu \mathrm{m}[7,10,11,31,32,41]$. Once particle size reduces below approximately $50 \mathrm{~nm}$, the biologic response diminishes [28]. A consensus around the role of particle volume and/or dose has not been reached $[10,11,22,31,38$, 41, 45].

Polyetheretherketone (PEEK) and its carbon fiber composites were introduced as bearing materials for TJAs in the 1990s [46]. As a result of its resistance to fatigue strain, radiologic transparency, and suitability for common sterilization techniques, unfilled or neat PEEK has already been widely used for spinal instrumentation [25]. Another specific benefit of using PEEK and its composites is its variable stiffness, usually facilitated by carbon fiber supplementation [27]. This principle was demonstrated by the development of carbon fiber-reinforced UHMWPE in the 1970s [40]. Carbon fiber-reinforced UHMWPE performed well tribologically in the laboratory [40] but was less successful in the clinic attributable, in part, to poor fatigue resistance and carbon fiber release [33, 48]. In a similar fashion, the mechanical properties of PEEK can be altered by adding carbon fibers [43]. The elastic modulus of carbon fiber-reinforced PEEK (CFR-PEEK) composites can be tailored to mimic the properties of cortical bone (18 GPa) or titanium alloy $(110 \mathrm{GPa})$. Carbon fiber orientation and length dictate these properties [43]. Perhaps, to mitigate a repeat performance of carbon fiber-reinforced UHMWPE, the implementation of clinically available PEEK-based devices has been slow. Only one carbon fiber-reinforced PEEK (CFR-PEEK) total hip arthroplasty (THA) (ABG II Hip System; Stryker SA, Montreux, CH) [35, 36] and one unfilled PEEK nucleus replacement device (NUBAC $^{\mathrm{TM}}$; Pioneer Surgical Technology, Marquette, MI, USA) [5] have been evaluated clinically. However, currently no PEEKbased TJA device has been cleared by the FDA for patient use, although the use of PEEK for cervical disc replacement [49] is under consideration. PEEK composites have shown in vitro wear properties comparable to metal-on-metal bearing couples $[5,38,46]$ and are commonly used in trauma implants and spinal fixation devices [25]. Although clinical trials are the gold standard assessment for biologic response, preclinical studies are a vital safeguard for patients and act as a potential predictor of clinical performance. In bulk form, PEEK composites generally are considered to be biocompatible [24, 47]. However, because many TJAs fail as a result of biologic responses to particles, it is imperative to identify whether or not the wear debris produced by PEEK devices is cytotoxic or immunologically reactive.

This systematic review therefore aimed to answer the following questions from preclinical and clinical studies: (1) What are the quantitative characteristics of PEEKbased wear particles produced by TJAs? (2) Do PEEK wear particles cause an adverse biologic response when compared with UHMWPE or a similar negative control biomaterial? (3) Is the biologic response affected by particle characteristics? 


\section{Search Strategy and Criteria}

We searched Embase (1947 to October 1, 2015) and Ovid MEDLINE (1946 to Week 1 of October 2015) for the following syntax: (1) (PEEK-OPTIMA or MITCH-PCR or MITCH or MOTIS or NUBAC).ti,ab; (2) (PEEK or PAEK or polyetheretherketone or polyaryletheretherketone or poly ether ether ketone or poly-ether-ether-ketone or poly ether-ether ketone or CFR-PEEK or carbon-fiber reinforced PEEK or carbon-fiber reinforced polyetheretherketone or PEK or carbon nanotube-reinforced PEEK or CNF-PEEK or CNF PEEK or all-PEEK).ti,ab; (3) (hip or knee or spine or spinal or disc or finger or metacarpophalangeal or total joint replacement or arthroplasty or joint replacement\$).ti,ab; (4) (particle\$ or particulate\$ or wear or debris or bulk).ti,ab; (5) (osteoly\$ or cytotoxic $\$$ or immunologic response or cytokine\$ or macrophage\$ or lymphocyte\$ or

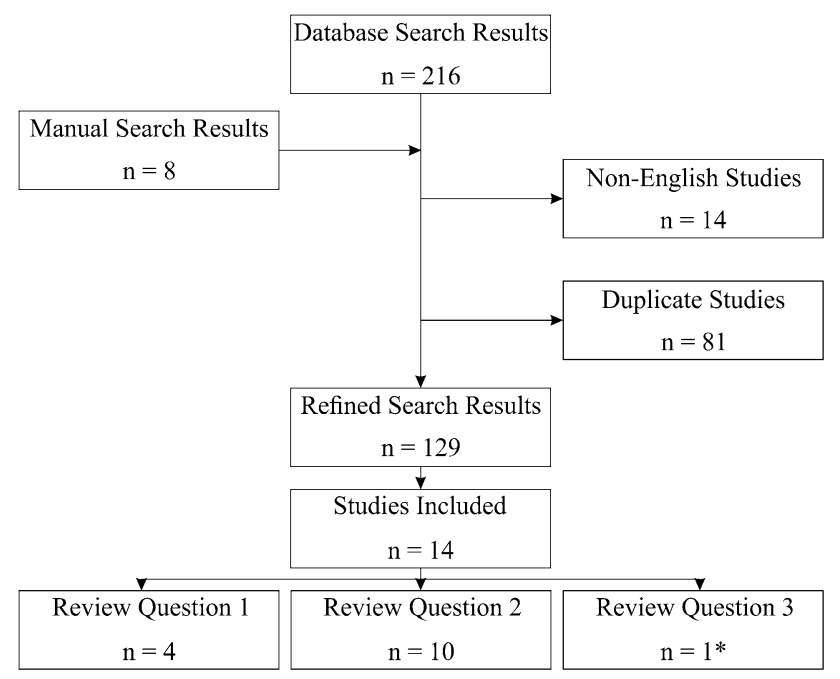

Fig. 1 Flow diagram shows the search strategy used. Asterisk denotes studies that were included for more than one question. monocyte\$ or RANK? or tumor necrosis factor or TNF\$ or interleukin or IL\$ or \$inflammatory).ti,ab; (6) (1) OR (2); (7) (4) OR (5); and (8) (3) AND (6) AND (7).

The search was limited to peer-reviewed articles published in English. We also searched Google Scholar, reference lists, and conference proceedings using similar terms. Both preclinical and clinical studies (including case studies) were included providing quantitative descriptors of particle characteristics. Articles not relevant to TJAs or reporting biologic responses not relevant to PEEK-based particles (such as contact cytotoxicity studies) were excluded. Two researchers (AAS-P, KMP) reviewed all of the studies independently. A third reviewer (CLB) clarified conflicting decisions (Fig. 1). The initial search retrieved 216 studies, 129 of which were checked, and 14 relevant studies were selected for interpretation and analysis. One study included both a human tissue histology analysis and an animal model.

A range of commercially available PEEK-based materials (Table 1) and custom-made variations were tested across the included studies. There were no detailed characterization studies of particles isolated from retrieved periprosthetic human tissue samples.

\section{Results}

Four in vitro studies quantified the characteristics of PEEKbased wear particles produced by TJAs, all of which generated particles in joint replacement simulators [5, 13-15] (Table 2). Four different joint replacements were included. Two types of total disc replacement were tested, one lumbar and one cervical device; and two types of knee replacement were assessed, a unicompartmental knee arthroplasty and a total knee arthroplasty (TKA) designed for patients with metal ion sensitivity. Six different bearing couples were analyzed, two of which featured in more than one study.

Table 1. Commercially available PEEK-based materials and products used in the included studies

\begin{tabular}{|c|c|c|c|}
\hline Material & Commercial name & Manufacturer & Reference \\
\hline Unfilled PEEK & PEEK-Optima LT1 & Invibio Ltd, Thornton-Cleveleys, UK & $\begin{array}{l}{[6]} \\
{[13]} \\
{[14]}\end{array}$ \\
\hline CRF-PEEK (Pan) & CFR-PEEK LT1 CA 30 & Invibio Ltd & $\begin{array}{l}{[44]} \\
{[13]} \\
{[14]}\end{array}$ \\
\hline CRF-PEEK (Pitch) & $\begin{array}{l}\text { ABG II Hip System } \\
\text { CFR-PEEK LT1 CP } 30\end{array}$ & $\begin{array}{l}\text { Stryker SA, Montreux, CH } \\
\text { Invibio Ltd }\end{array}$ & $\begin{array}{l}{[35]} \\
{[26]} \\
{[44]}\end{array}$ \\
\hline
\end{tabular}

CRF-PEEK $($ Pan) = PEEK containing 30\% polyacrylonitrile based carbon fibers; CRF-PEEK (Pitch) = PEEK with a carbon fiber reinforcement of $30 \%$ pitch fibers; PEEK = polyetheretherketone. 


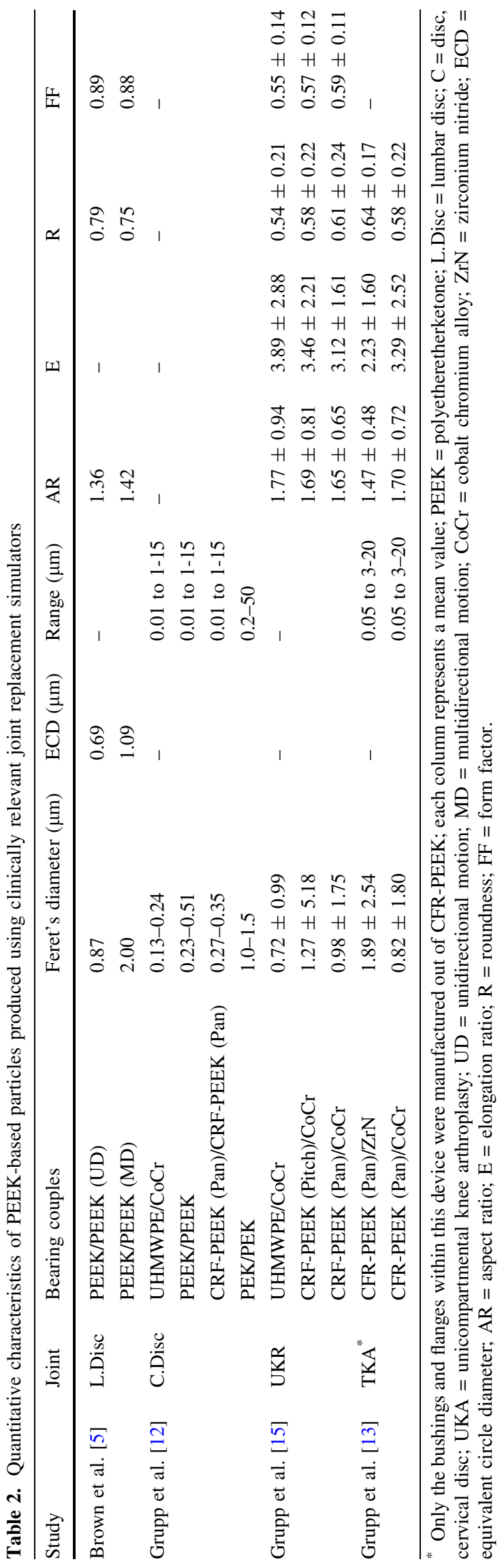

Feret's diameter, the distance between two parallel planes constraining each particle, was the most commonly reported descriptor of particle size. The mean particle size (Feret's diameter) reported by the studies was $0.23 \mu \mathrm{m}$ to $2.0 \mu \mathrm{m}$ with the absolute range of approximately $0.01 \mu \mathrm{m}$ to $50 \mu \mathrm{m}$. Self-mating unfilled PEEK bearings were tested for both cervical and lumbar disc replacement devices. Lumbar disc replacement devices produced larger particles than the cervical disc devices using the same bearing materials. CFR-PEEK (Pan)-on-cobalt chromium alloy bearings were tested in both knee arthroplasty studies. The size and morphology of particles were similar but the origin of particles was different. For example, Grupp et al. [15] measured particles from the primary articulation, whereas Grupp et al. [13] analyzed debris from bushings and flanges used within the TKA design.

Ten studies investigated the biologic response to PEEKbased particles [6, 12, 17, 19, 23, 26, 29, 34, 35, 44]. Two studies performed histologic analysis on retrieved human tissue from failed THAs [26, 35] (Table 3). Evidence of rod-like and granular particles phagocytozed by macrophages was reported but not attributed to wear debrisinduced failure. Six studies used in vivo animal models (rat, mouse, and rabbit) to investigate responses to PEEKbased particles [6, 12, 23, 26, 29, 44] (Table 4). All three studies focusing on the spine identified a mild inflammatory response that was local to the particles within the epidural space. Using qualitative histologic descriptions, the immunologic response was not different from the UHMWPE particle groups with the number of studies available [6, 12, 23]. Cunningham et al. [6] was the only animal study to show a reduction in expression of inflammatory cytokines associated with unfilled PEEK particles when compared with UHMWPE particles of the same size. Two studies analyzed particles composed of two CFRPEEK composites, CFR-PEEK (Pitch) and CFR-PEEK (Pan). (Pitch-based carbon fibers are produced using coal tar pitch and pan-based carbon fibers use polyacrylonitrile [Pan] as an initial processing material [9]. Pitch-based and Pan-based composites exhibit different mechanical properties and can be tailored by the manufacturer [43].) Depending on the cytokine (interleukin [IL]-1 $\beta$, IL-6, or tumor necrosis factor- $\alpha$ ) and area investigated (bone marrow, synovium, or cartilage), the increase of cytokine release cause by CFR-PEEK (Pitch) ranged between twoand sevenfold when compared with the UHMWPE control [29]. To a lesser and statistically significant extent, CFRPEEK (Pan) particles caused an increase in cytokine expression in bone marrow tissue relative to UHMWPE particles. This was the only study to report adverse tissue reactions to PEEK-based particles when compared with UHMWPE particles. Three studies used in vitro cell lines to assess the biocompatibility of PEEK-based particles 
Table 3. Human tissue retrieval studies after total joint arthroplasty failure

\begin{tabular}{|c|c|c|c|c|c|c|}
\hline Study & Joint & Device & $\begin{array}{l}\text { Bearing } \\
\text { couple }\end{array}$ & Tissue type & Analysis & Outcomes \\
\hline $\begin{array}{l}\text { Latif et al. } \\
\qquad[26]^{*}\end{array}$ & THA & $\begin{array}{l}\text { ABG II, Stryker } \\
\text { Orthopaedics, } \\
\text { Mahwah, NJ, USA }\end{array}$ & $\begin{array}{l}\text { CFR-PEEK/ } \\
\text { alumina }\end{array}$ & Synovium & Histology & $\begin{array}{l}\text { Implantation time: not specified } \\
\text { Outcomes: visual inspection; histology (stain no } \\
\text { specified) } \\
\text { Results: tissue was gray/black but no synovial } \\
\text { hypertrophy; histology showed connective } \\
\text { tissue of varying density with dark material } \\
\text { present within; phagocytozed particles eviden } \\
\text { within macrophages; rod-like particles and } \\
\text { smaller granular particles present; no } \\
\text { accumulation of lymphocytes or leucocytes } \\
\text { around blood vessels }\end{array}$ \\
\hline $\begin{array}{l}\text { Pace et al. } \\
{[35]^{*}}\end{array}$ & THA & $\begin{array}{c}\text { ABG II, Stryker } \\
\text { Orthopaedics }\end{array}$ & $\begin{array}{l}\text { CFR-PEEK/ } \\
\text { alumina }\end{array}$ & $\begin{array}{l}\text { Granulomatous } \\
\text { periprosthetic } \\
\text { tissue }\end{array}$ & Histology & $\begin{array}{l}\text { Implantation time: } 26 \text { months } \\
\text { Outcomes: histology (stain not specified) } \\
\text { Results: connective tissue of varying density } \\
\text { evident with areas of highly vascularized } \\
\text { granulation tissue; neutrophilic granulocyte, } \\
\text { lymphocyte, and plasma cell infiltration } \\
\text { evident; perivascular macrophages contained } \\
\text { small highly reflective metal particles, larger } \\
\text { black particles suggested to be carbon and } \\
\text { colorless granular particles exhibiting intense } \\
\text { birefringence thought to be of polymer origin }\end{array}$ \\
\hline
\end{tabular}

* Retrieved tissue from participants of the same clinical trial; CFR-PEEK = carbon fiber-reinforced polyetheretherketone.

$[17,19,34]$ (Table 5). Two studies found that PEEK-based particles performed similarly to those of UHMWPE particles, ie, did not display evidence of cytotoxicity elicited by the particles [19, 34]. Hallab et al. [17] reported a reduction in both lactate dehydrogenase (LDH) activity and inflammatory cytokine release for PEEK particles relative to UHMWPE particles, which suggested PEEK particles were less biologically reactive than UHMWPE particles in this study.

The in vitro study by Hallab et al. [17] was the only study to associate particle characteristics with biologic response. Unfilled PEEK particles, in the largest size range (approximately $13 \mu \mathrm{m}$ ), reduced macrophage viability, but by no more than $20 \%$ of the "medium only" control group (ie, cells with no particles). In the same study, UHMWPE particles, regardless of size, also caused cytotoxic effects. No study directly compared unfilled PEEK against a CFRPEEK composite, which may reflect manufacturer application preferences for each PEEK type. All of the laboratory studies included in this review used commercially purchased or processed particles that were produced predominantly by cryomilling and/or cryopulverization. Only five of the studies reported quantitative particle characteristics for their biocompatibility testing, four of which used particles produced by cryomilling or cryopulverization [6, 12, 17, 29, 44] (Table 6). Grupp et al. [12] and Utzschneider et al. [44] artificially manufactured particles to replicate their simulator-generated particles for both size and morphology.

\section{Discussion}

Human tissue particle isolation studies are required to definitively determine TJA wear particle characteristics. No such study was identified and therefore in vivo particle characteristics have not been confirmed or included in this review. However, validated TJA wear simulation is an accepted methodology used in the generation of wear debris associated with specific TJAs. This review identified that there is a lack of clinical studies focused on the wear particles produced by PEEK-based TJAs; therefore, wear simulation and preclinical studies formed the majority of studies used to answer the three main questions: (1) What are the quantitative characteristics of PEEK-based wear particles produced by TJAs? (2) Do PEEK wear particles cause an adverse biologic response when compared with UHMWPE or a similar negative control biomaterial? (3) Is the biologic response affected by particle characteristics? From the relatively small number of studies included, it was found that wear debris produced by PEEK-based bearings was within the phagocytozable size range $(0.1-10 \mu \mathrm{m})$ and exhibited comparable cytotoxic effects to UHMWPE particles despite a varied cytokine response across the studies. 
Table 4. In vivo animal model studies testing biocompatibility

\begin{tabular}{|c|c|c|c|c|c|c|}
\hline Study & Animal & Model & Test material & $\begin{array}{l}\text { UHMWPE } \\
\text { comparator? }\end{array}$ & Outcomes & $\begin{array}{l}\text { Relative } \\
\text { reactivity }\end{array}$ \\
\hline Latif et al. [26] & Rat & Air pouch & CFR-PEEK & Yes $^{*}$ & $\begin{array}{l}\text { Test intervals: 1, 3, and } 10 \text { days; outcomes: visual } \\
\text { scoring system; pouch thickness; localization of } \\
\text { macrophages (ED1 antigen staining); vascular } \\
\text { proliferation (ICAM1 staining); results: visual } \\
\text { scoring system showed PE to cause more inflamed } \\
\text { than CFR-PEEK; no differences in pouch } \\
\text { thickness for all variables; no difference between } \\
\text { polyethylene and CRF-PEEK for ED1 staining or } \\
\text { ICAM1 staining }\end{array}$ & - \\
\hline Kabir et al. [23] & Rabbit & Epidural & PEK & Yes & $\begin{array}{l}\text { Test intervals: } 3 \text { and } 6 \text { months; outcomes: } \\
\text { neurobehavioral observations (weekly); } \\
\text { inflammation identified via histology; results: no } \\
\text { neurological deficits or systemic toxicity; } \\
\text { crystalline wear debris identified and surrounded } \\
\text { by inflammatory cells; inflammation and } \\
\text { angiogenesis limited to periparticle epidural space }\end{array}$ & - \\
\hline $\begin{array}{l}\text { Utzschneider } \\
\text { et al. }[44]^{\dagger}\end{array}$ & Mouse & Knee & $\begin{array}{l}\text { CRF-PEEK (pitch) } \\
\text { CRF-PEEK (Pan) }\end{array}$ & Yes & $\begin{array}{l}\text { Test intervals: } 1 \text { week; outcomes: synovial } \\
\text { microcirculation assessment; fraction of rolling } \\
\text { leukocytes; histology (H\&E); synovial membrane } \\
\text { thickness; results: no difference in functional } \\
\text { capillary density, fraction of rolling leukocytes, } \\
\text { nor the number of leukocytes adhered to the } \\
\text { endothelium between particle groups; no } \\
\text { differences in histological scoring for } \\
\text { inflammation or synovial membrane thickness } \\
\text { were identified between particle groups; the } \\
\text { control group had a significant reduction in each } \\
\text { of the aforementioned variables compared with } \\
\text { the particle groups }\end{array}$ & - \\
\hline $\begin{array}{l}\text { Cunningham } \\
\text { et al. [6] }\end{array}$ & Rabbit & Epidural & PEEK & Yes & $\begin{array}{l}\text { Test intervals: } 3 \text { and } 6 \text { months; outcomes: histology } \\
\text { (H\&E and HAM-56 staining); cytokine analysis } \\
\text { (ABC method; TNF- } \alpha \text {, TNF- } \beta \text {, IL- } 1 \alpha \text {, IL-1 } \beta \text {, and } \\
\text { IL-6); results: PEEK exhibited a reduced cytokine } \\
\text { expression relative to UHMWPE }\end{array}$ & $(-)$ \\
\hline $\begin{array}{l}\text { Lorber et al. } \\
{[29]^{\dagger}}\end{array}$ & Mouse & Knee & $\begin{array}{l}\text { CRF-PEEK (pitch) } \\
\text { CRF-PEEK (Pan) }\end{array}$ & Yes & $\begin{array}{l}\text { Test intervals: } 1 \text { week; outcomes: cytokine analysis } \\
\text { (ABC method; TNF- } \alpha \text {, IL-1 } \beta \text {, and IL-6); results: } \\
\text { CFR-PEEK (pitch) particles showed significantly } \\
\text { increased expression of: TNF- } \alpha \text {, IL-1 } \beta \text {, and IL-6 } \\
\text { in articular cartilage and bone marrow, and TNF- } \\
\alpha \text { in the synovial layer when compared with the } \\
\text { UHMWPE group; CFR-PEEK (Pan) particles } \\
\text { caused increased TNF- } \alpha \text { and IL-1 } \beta \text { levels in bone } \\
\text { marrow compared with UHMWPE particles }\end{array}$ & $(+)$ \\
\hline Grupp et al. [12] & Rabbit & Epidural & CRF-PEEK & Yes & $\begin{array}{l}\text { Test intervals: } 3 \text { and } 6 \text { months; outcomes: histology } \\
\text { (stain not specified); results: wear debris particles } \\
\text { surrounded by inflammatory cells were identified } \\
\text { in the vertebral canal; inflammation was limited to } \\
\text { the epidural space; CFR-PEEK showed a similar } \\
\text { histopathological reaction to UHMWPE particles }\end{array}$ & - \\
\hline
\end{tabular}

* Type of polyethylene not specified; ${ }^{\dagger}$ related studies; $(+)=$ increased reactivity; $(-)=$ decreased reactivity; $-=$ similar reactivity; reactivity was judged relative to the within study UHMWPE control; CFR-PEEK = carbon fiber-reinforced polyetheretherketone; ICAM1 = intercellular adhesion molecule 1; H\&E = hematoxylin and eosin; TNF = tumor necrosis factor; IL = interleukin.

Several limitations were apparent as we surveyed the available evidence. No studies to date have isolated and characterized particles from retrieved human periprosthetic tissue. Therefore, the true clinical relevance of particle size and morphology distributions produced by simulators for each joint remains unknown. Although Utzschneider et al. [44] and Grupp et al. [12] replicated simulator-generated particle size distributions and morphology accurately, 


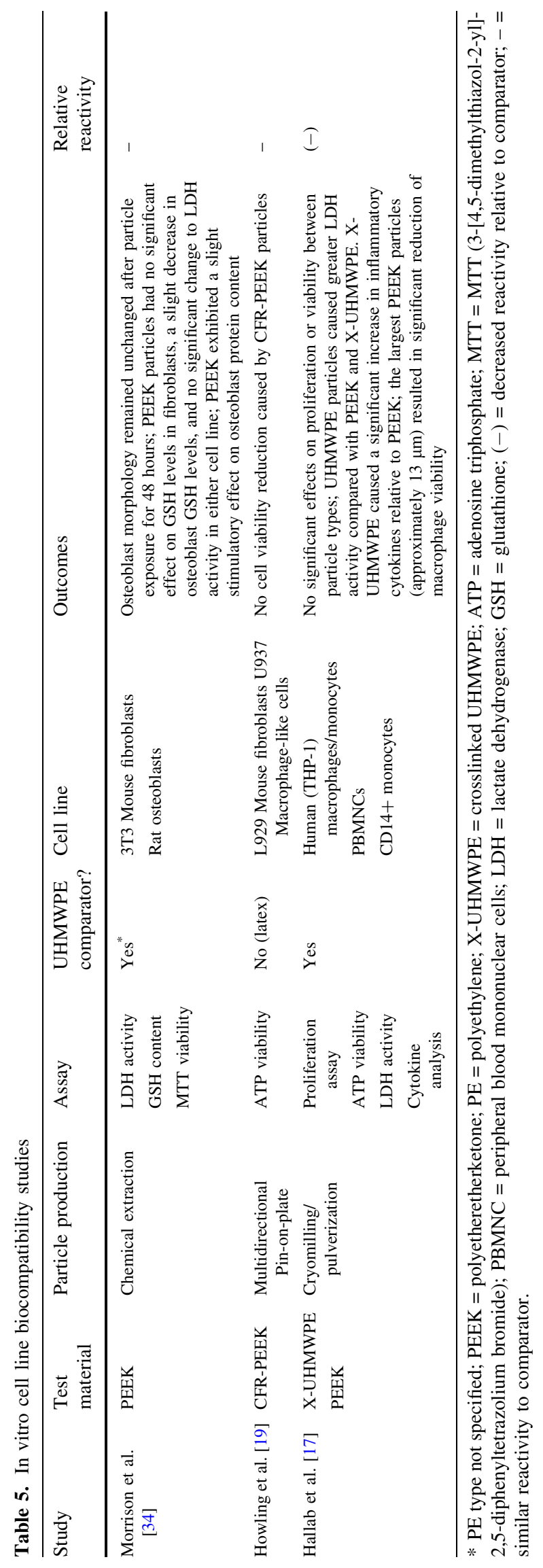




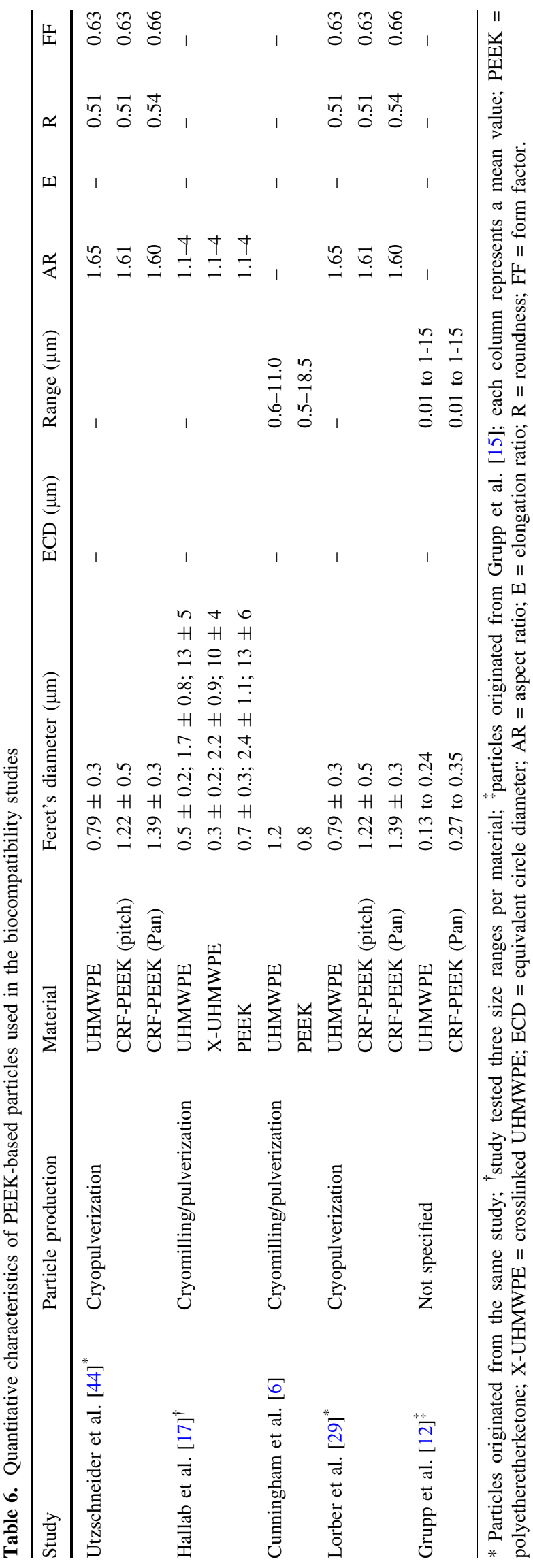

particle production methods such as cryomilling or cryopulverization may not produce relevant particle surface characteristics that are important for particle cell membrane interactions for biologic response experiments. The negative control in most studies consisted of UHMWPE particles. PEEK is an alternative bearing material to more modern UHMWPE formulations (such as highly crosslinked UHMWPE and vitamin $\mathrm{E}$ infused or other antioxidant-containing highly crosslinked UHMWPE) and hard-on-hard bearings. Therefore, using conventional UHMWPE particles as a control does not compare like for like with the other commonly used alternatives to PEEK. The biologic response identified in human histology studies such as the investigation by Pace et al. [35] was confounded by particles produced from other interfaces of the joint replacement device, eg, the fixation surface. Emulation of in vivo conditions with in vitro experiments is a challenge. Each study assessing cytotoxicity used different cell lines and varying particle doses and volumes making comparisons between studies inappropriate. Moreover, current polymer isolation methods exploit material density to separate wear debris particles from proteins (ie, UHMWPE particles are buoyant in water, whereas proteins sink). Human proteins and PEEK particles have similar densities (approximately $1.3 \mathrm{~g} / \mathrm{cc}$ ), meaning a new particle isolation method may be required to retrieve PEEK particles from tissue samples or simulator lubricant.

The mean particle size for PEEK-based material bearing couples was within the $0.1-\mu \mathrm{m}$ to $10-\mu \mathrm{m}$ size range limit, which is generally accepted as the most biologically reactive. The absolute range reported was approximately $0.01 \mu \mathrm{m}$ to $50 \mu \mathrm{m}$. Most devices produced particles in the submicron size range, which was consistent with other polymer articulations such as UHMWPE-on-cobalt chromium alloy [14, 15]. However, these particle characteristics were determined from only four simulator studies and from devices that are not commonly implanted. The two total disc replacements, one lumbar device and one cervical device, both self-mating unfilled PEEK implants, showed up to a 8.7 times difference in mean particle diameter. The lumbar total disc replacement had the largest mean particle size of the two disc replacement types $(2 \mu \mathrm{m})$, possibly as a result of different testing protocols (such as using higher loads and greater ROM) relative to the cervical total disc replacement [3]. CFRPEEK (Pan)-on-cobalt chromium alloy was another bearing couple investigated, although one joint was a unicompartmental knee with a CFR-PEEK (Pan) primary articulation. The other joint was a TKA developed for patients with metal ion sensitivity and used CFR-PEEK (Pan) for bushings and flanges. The wear particles produced by the two devices were similar in size and morphology despite the method of articulation being 
substantially different. The similarity in particle characteristics may indicate a common wear mode, although a comprehensive damage mode assessment would be required to draw such conclusions and is a recommendation for future studies. Unlike conventional THA and TKA simulation, the clinical relevance of the particles produced in simulator studies analyzing experimental joint replacement devices and/or using novel biomaterials such as PEEK needs to be validated against wear debris isolated from retrieved human tissue samples. No human tissue PEEK-based wear particle isolation studies were identified within this review.

In vivo histopathologic analyses were the most prevalent biocompatibility testing mode used for PEEK-based particles. Histology is a useful tool to retrospectively identify the end condition of the tissue sample location. The two human tissue sample retrieval studies were case studies, each with a sample size of one. Although neither study reported an immunologic response as the cause of failure, generalizable conclusions based on these case studies cannot be made. The animal studies included in this review showed PEEK particles have a minimal effect on immunologic cell recruitment, an indicator of immunologic response, when compared with UHMWPE particles. A similar immunologic response, identified using histology, was reported for unfilled PEEK wear particles produced by spinal instrumentation [39]. Despite the majority of the animal studies showing a comparable biologic response between particle groups, the range of different methods and anatomic test locations means the results cannot be generalized with the limited literature available. The in vitro cytotoxicity studies reported either no or low suppression of macrophage viability and no substantial changes to LDH activity or glutathione content. Different assays and cell lines were used between studies, which limited relevant comparisons. The clinical relevance of artificially manufactured particles used in animal studies requires further investigation.

Particle size, morphology, volume (or dose), and composition are associated with biologic reactivity [29]. Hallab et al. [17] was the only study included in this review to test particle size effects on cytotoxicity. It is generally accepted that particles in the phagocytozable size range $(0.1-10 \mu \mathrm{m})$ are the most biologically reactive [7, 10, 11, 31, 32, 41]; however, Hallab et al. [17] found the largest PEEK particles (approximately $13 \mu \mathrm{m}$ ) to have a cytotoxic effect. However, in the same study, UHMWPE particles, regardless of size, also caused cytotoxic effects. These results should be viewed with caution, because UHMWPE should not have adverse effects on cell viability. This may be a consequence of the particle manufacturing process. For instance, cryomilling often uses a surfactant during the milling process that can be degraded (eg, serum) or toxic to cells (eg, oleic acid). The cytotoxicity observed for both the UHMWPE and PEEK particles is therefore likely a consequence of contamination. The clinical relevance of PEEK particles in the $>10-\mu \mathrm{m}$ size range is yet to be determined, although at least two of the simulator studies identified by this review isolated and characterized particles in the $>10-\mu \mathrm{m}$ size range. Other factors to consider when interpreting particle biocompatibility studies include whether the particles produced by cryomilling/pulverization differ in surface characteristics (eg, surface topography and the presence of endotoxins) that could have an effect on cell behavior. Additionally, a complex relationship exists among particle size, debris volume, and tissue volume that has not been completely elucidated for UHMWPE particles [10, 11, 22, 31, 38, 41, 45] let alone PEEK particles, which may provide additional factors to consider independently of particle size and morphology such as surface chemistry (eg, hydrophilicity) or the prescence of carbon fiber particles and their characteristics.

Polyetheretherketone and its carbon composites are polymers that have customizable mechanical properties suitable for orthopaedic applications [43], high-performing in vitro biotribologic properties [4], and are biocompatible in bulk form [24, 47]. However, in light of CFRUHMWPE device failure in the decades before the implementation of the current preclinical testing standards [48], the biologic response to PEEK wear debris must be investigated. From the published evidence included in this review [5, 6, 12-15, 17, 19, 23, 26, 29, 34, 35, 44], wear particles produced by PEEK-based bearings in TJA wear simulators were, in almost all cases, in the phagocytozable size range $(0.1-10 \mu \mathrm{m})$. Despite this, the biologic response to PEEK-based particles has thus far been generally found not to cause cytotoxic effects, but was variable when considering inflammatory cytokine release. It should be noted that only 10 studies were identified in this review to have investigated the biologic response to PEEK-based particles from TJAs, all of which used model particles or particles generated by cryomilling/cryopulverization. Before preclinical assessments of biologic response can accurately reflect the cell interactions with PEEK-based particles, in vivo generated wear particle characteristics must be determined. The first step to identifying clinically relevant particle characteristics is to perform human tissue retrieval studies with subsequent particle isolation and characterization analyses. None have been completed for PEEK-based TJA wear particles thus far. Once the wear particle characteristics have been identified, the size and morphologies can be emulated by joint replacement simulators, isolated, and immunologically tested in cell studies. These steps are required before the biologic response to PEEK-based particles can be determined accurately and repeatably. 
Open Access This article is distributed under the terms of the Creative Commons Attribution 4.0 International License (http:// creativecommons.org/licenses/by/4.0/), which permits unrestricted use, distribution, and reproduction in any medium, provided you give appropriate credit to the original author(s) and the source, provide a link to the Creative Commons license, and indicate if changes were made.

\section{References}

1. Amstutz HC, Campbell P, Kossovsky N, Clarke IC. Mechanism and clinical significance of wear debris-induced osteolysis. Clin Orthop Relat Res. 1992;276:7-18.

2. Bladen C, Teramura S, Russell S, Fujiwara K, Fisher J, Ingham E, Tomita N, Tipper J. Analysis of wear, wear particles, and reduced inflammatory potential of vitamin E ultrahigh-molecular-weight polyethylene for use in total joint replacement. J Biomed Mater Res B Appl Biomater. 2013;101:458-466.

3. British Standards Institute. Implants for surgery-wear of total intervertebral spinal disc prostheses Part 1: Loading and displacement parameters for wear testing and corresponding environmental conditions for test.: British Standards Online [Online]; 2011. Available at: https://bsol.bsigroup.com/. Accessed June 29, 2016.

4. Brockett CL, John G, Williams S, Jin Z, Isaac GH, Fisher J. Wear of ceramic-on-carbon fiber-reinforced poly-ether ether ketone hip replacements. $J$ Biomed Mater Res B Appl Biomater. 2012;100:1459-1465.

5. Brown T, Bao QB, Kilpela T, Songer M. An in vitro biotribological assessment of NUBAC, a polyetheretherketone-onpolyetheretherketone articulating nucleus replacement device: Methodology and results from a series of wear tests using different motion profiles, test frequencies, and environmental conditions. Spine. 2010;35:E774-E781.

6. Cunningham BW, Hallab NJ, Hu N, McAfee PC. Epidural application of spinal instrumentation particulate wear debris: a comprehensive evaluation of neurotoxicity using an in vivo animal model Laboratory investigation. $J$ Neurosurg Spine. 2013;19:336-350.

7. Glant TT, Jacobs JJ. Response of three murine macrophage populations to particulate debris: bone resorption in organ cultures. J Orthop Res. 1994;12:720-731.

8. Goodman SB. Wear particles, periprosthetic osteolysis and the immune system. Biomaterials. 2007;28:5044-5048.

9. Green S. Compounds and composite materials. In: Kurtz, SM. PEEK Biomaterials Handbook. Oxford, UK: William Andrew Publishing; 2012:23-48.

10. Green T, Fisher J, Stone M, Wroblewski B, Ingham E. Polyethylene particles of a 'critical size' are necessary for the induction of cytokines by macrophages in vitro. Biomaterials. 1998;19:2297-2302.

11. Green TR, Fisher J, Matthews JB, Stone MH, Ingham E. Effect of size and dose on bone resorption activity of macrophages by in vitro clinically relevant ultra high molecular weight polyethylene particles. J Biomed Mater Res. 2000;53:490-497.

12. Grupp T, Kabir K, Fritz B, Schwiesau J, Bloemer W, Jansson V. Evaluation of carbon-fibre-reinforced PEEK as material for intervertebral disc replacement. Bone Joint J. 2014;96:223-223.

13. Grupp TM, Giurea A, Miehlke RK, Hintner M, Gaisser M, Schilling C, Schwiesau J, Kaddick C. Biotribology of a new bearing material combination in a rotating hinge knee articulation. Acta Biomater. 2013;9:7054-7063.

14. Grupp TM, Meisel HJ, Cotton JA, Schwiesau J, Fritz B, Blomer W, Jansson V. Alternative bearing materials for intervertebral disc arthroplasty. Biomaterials. 2010;31:523-531.
15. Grupp TM, Utzschneider S, Schroder C, Schwiesau J, Fritz B, Maas A, Blomer W, Jansson V. Biotribology of alternative bearing materials for unicompartmental knee arthroplasty. Acta Biomater. 2010;6:3601-3610.

16. Hallab NJ, Anderson S, Stafford T, Glant T, Jacobs JJ. Lymphocyte responses in patients with total hip arthroplasty. J Orthop Res. 2005;23:384-391.

17. Hallab NJ, McAllister K, Brady M, Jarman-Smith M. Macrophage reactivity to different polymers demonstrates particle sizeand material-specific reactivity: PEEK-OPTIMA $®$ particles versus UHMWPE particles in the submicron, micron, and 10 micron size ranges. J Biomed Mater Res B Appl Biomater. 2012;100:480-492.

18. Holt G, Murnaghan C, Reilly J, Meek R. The biology of aseptic osteolysis. Clin Orthop Relat Res. 2007;460:240-252.

19. Howling GI, Sakoda H, Antonarulrajah A, Marrs H, Stewart TD, Appleyard S, Rand B, Fisher J, Ingham E. Biological response to wear debris generated in carbon based composites as potential bearing surfaces for artificial hip joints. J Biomed Mater Res B Appl Biomater. 2003;67:758-764.

20. Illgen RL, Forsythe TM, Pike JW, Laurent MP, Blanchard CR. Highly crosslinked vs conventional polyethylene particles-an in vitro comparison of biologic activities. J Arthroplasty. 2008;23:721-731.

21. Ingham E, Fisher J. Biological reactions to wear debris in total joint replacement. Proc Inst Mech Eng H. 2000;214:21-37.

22. Ingram J, Matthews JB, Tipper J, Stone M, Fisher J, Ingham E. Comparison of the biological activity of grade GUR 1120 and GUR 415HP UHMWPE wear debris. Biomed Mater Eng. 2001;12:177-188.

23. Kabir K, Schwiesau J, Pflugmacher R, Burger C, Grupp T, Wirtz D. Comparision of biological response to PEK and UHMWPEWear debris in epidural space. Eur Spine J. 2010;19:2059-2060.

24. Katzer A, Marquardt H, Westendorf J, Wening J, Von Foerster G. Polyetheretherketone-cytotoxicity and mutagenicity in vitro. Biomaterials. 2002;23:1749-1759.

25. Kurtz SM, Devine JN. PEEK biomaterials in trauma, orthopedic, and spinal implants. Biomaterials. 2007;28:4845-4869.

26. Latif AM, Mehats A, Elcocks M, Rushton N, Field RE, Jones E. Pre-clinical studies to validate the Mitch $\mathrm{PCR}^{\mathrm{TM}}$ cup: a flexible and anatomically shaped acetabular component with novel bearing characteristics. Journal of Materials Science: Materials in Medicine. 2008;19:1729-1736.

27. Li CS, Vannabouathong C, Sprague S, Bhandari M. The use of carbon-fiber-reinforced (CFR) PEEK material in orthopedic implants: a systematic review. Clin Med Insights Arthritis Musculoskelet Disord. 2015;8:33.

28. Liu A, Richards L, Bladen CL, Ingham E, Fisher J, Tipper JL. The biological response to nanometre-sized polymer particles. Acta Biomater. 2015;23:38-51.

29. Lorber V, Paulus AC, Buschmann A, Schmitt B, Grupp TM, Jansson V, Utzschneider S. Elevated cytokine expression of different PEEK wear particles compared to UHMWPE in vivo. $J$ Mater Sci Mater Med. 2014;25:141-149.

30. Ma T, Goodman S. Biological effects of wear debris from joint arthroplasties. In: Wnek GE, Bowlin GL, eds. Encyclopedia of Biomaterials and Biomedical Engineering. London, UK: Informa Healthcare; 2008.

31. Matthews JB, Besong AA, Green TR, Stone MH, Wroblewski $\mathrm{BM}$, Fisher J, Ingham E. Evaluation of the response of primary human peripheral blood mononuclear phagocytes to challenge with in vitro generated clinically relevant UHMWPE particles of known size and dose. J Biomed Mater Res. 2000;52:296-307.

32. Matthews JB, Green TR, Stone MH, Wroblewski BM, Fisher J, Ingham E. Comparison of the response of primary murine peritoneal macrophages and the U937 human histiocytic cell line to 
challenge with in vitro generated clinically relevant UHMWPE particles. Biomed Mater Eng. 1999;10:229-240.

33. Medel F, Kurtz SM, Klein GR, Levine H, Sharkey P, Austin M, Kraay M, Rimnac CM. Clinical, surface damage and oxidative performance of poly II tibial inserts after long-term implantation. J Long Term Eff Med Implants. 2008;18:151-165.

34. Morrison C, Macnair R, MacDonald C, Wykman A, Goldie I, Grant MH. In vitro biocompatibility testing of polymers for orthopaedic implants using cultured fibroblasts and osteoblasts. Biomaterials. 1995; 16:987-992.

35. Pace N, Marinelli M, Spurio S. Technical and histologic analysis of a retrieved carbon fiber-reinforced poly-ether-ether-ketone composite alumina-bearing liner 28 months after implantation. $J$ Arthroplasty. 2008;23:151-155.

36. Pace N, Spurio S, Rizzato G. Clinical trial of a new CF-PEEK acetabular insert in hip arthroplasty. Hip Int. 2004;14:132-133.

37. Pizzoferrato A, Ciapetti G, Stea S, Toni A. Cellular events in the mechanisms of prosthesis loosening. Clin Mater. 1991;7:51-81.

38. Rader CP, Sterner T, Jakob F, Schütze N, Eulert J. Cytokine response of human macrophage-like cells after contact with polyethylene and pure titanium particles. $J$ Arthroplasty. 1999;14:840-848.

39. Rivard $\mathrm{CH}$, Rhalmi S, Coillard C. In vivo biocompatibility testing of PEEK polymer for a spinal implant system: a study in rabbits. J Biomed Mater Res. 2002;62:488-498.

40. Sclippa E, Piekarski K. Carbon fiber reinforced polyethylene for possible orthopedic uses. J Biomed Mater Res. 1973;7:59-70.

41. Shanbhag AS, Jacobs JJ, Black J, Galante JO, Glant TT. Human monocyte response to particulate biomaterials generated in vivo and in vitro. J Orthop Res. 1995;13:792-801.
42. Sieving A, Wu B, Mayton L, Nasser S, Wooley PH. Morphological characteristics of total joint arthroplasty-derived ultrahigh molecular weight polyethylene (UHMWPE) wear debris that provoke inflammation in a murine model of inflammation. $J$ Biomed Mater Res A. 2003;64:457-464.

43. Skinner HB. Composite technology for total hip arthroplasty. Clin Orthop Relat Res. 1988;235:224-236.

44. Utzschneider S, Becker F, Grupp TM, Sievers B, Paulus A, Gottschalk O, Jansson V. Inflammatory response against different carbon fiber-reinforced PEEK wear particles compared with UHMWPE in vivo. Acta Biomater. 2010;6:4296-4304.

45. von Knoch M, Jewison DE, Sibonga JD, Sprecher C, Morrey BF, Loer F, Berry DJ, Scully SP. The effectiveness of polyethylene versus titanium particles in inducing osteolysis in vivo. J Orthop Res. 2004;22:237-243.

46. Wang A, Lin R, Stark C, Dumbleton J. Suitability and limitations of carbon fiber reinforced PEEK composites as bearing surfaces for total joint replacements. Wear. 1999;225:724-727.

47. Williams D, McNamara A, Turner R. Potential of polyetheretherketone (PEEK) and carbon-fibre-reinforced PEEK in medical applications. J Mater Sci Lett. 1987;6:188-190.

48. Wright T, Astion D, Bansal M, Rimnac C, Green T, Insall J, Robinson R. Failure of carbon fiber-reinforced polyethylene total knee-replacement components. A report of two cases. J Bone Joint Surg Am. 1988;70:926-932.

49. Xin H, Shepherd D, Dearn K. A tribological assessment of a PEEK based self-mating total cervical disc replacement. Wear. 2013;303:473-479. 